\title{
Las huellas del conflicto armado en la salud mental colectiva
}

\section{The traces of armed conflict in collective mental health}

\author{
iD Elisa Jojoa Tobar¹; iD Jesús Andrés Bonilla Muñoz²; iD Nory Estefanía López Guerrero³; \\ Aura Milena Muñoz Oviedo 4
}

\begin{abstract}
Resumen
En el marco del proceso de implementación del Modelo Integral de Atención en Salud - MIAS, es necesario reconocer y comprender el impacto que el conflicto armado ha ejercido sobre la salud mental, especialmente en los territorios más afectados. Este artículo parte de la investigación denominada "Salud mental colectiva: impactos en población afectada por conflicto armado. Caldono, Cauca. 2017" y aporta elementos para el desarrollo de intervenciones de Promoción de la Salud Mental Colectiva, considerando que para ello; la paz, la justicia social, las condiciones de vivienda aceptables, la educación y el empleo (OMS, 2004) son requisitos indispensables, de tal manera que la identificación y descripción de las afectaciones que ha generado el conflicto armado sobre la relación familia-comunidad-territorio en el Municipio de Caldono, Cauca, se constituyen en insumos para el desarrollo de intervenciones en un escenario de posconflicto. El objetivo fue reconocer el impacto que el conflicto armado ha generado en la salud mental colectiva de la comunidad indígena y campesina del municipio de Caldono desde la relación familia-comunidad-territorio. Esta investigación cualitativa fenomenológica, utilizó para la recolección de información la observación y entrevistas a profundidad con informantes claves. La información obtenida se organizó de acuerdo a las dimensiones de la estructura social y cultural propuestas en la teoría del Sol Naciente de Madeleine Leininger, identificando que la comunidad de Caldono, por sus experiencias con el conflicto armado presenta una afectación en la salud mental colectiva evidenciada por heridas invisibles de la guerra; logrando en la recolección de información reconocer diferentes problemáticas que afectan la comunidad y el territorio, entre ellas el sufrimiento humano, la estigmatización social y territorial y la desesperanza, entre otros. Así mismo, emergen entorno a los eventos traumáticos otras experiencias que han contribuido a fortalecer sus procesos colectivos de organización, solidaridad y resistencia, como estrategias para la conservación de la vida y del derecho a habitar en sus territorios.
\end{abstract}

Palabras claves: Salud Mental Colectiva, conflicto armado, impacto, familia, comunidad y territorio.

\footnotetext{
${ }^{1}$ Magister en Salud Intercultural. Docente Ocasional Tiempo Completo. Departamento de Enfermería, Facultad Ciencias de la Salud, Universidad del Cauca. Colombia. Correo electrónico: elisaj@unicauca.edu.co. ORCID ID: 0000-0002-7538-6505.

${ }^{2}$ Enfermero. Egresado del Departamento de Enfermería, Facultad Ciencias de la Salud, Universidad del Cauca. Colombia. Correo electrónico: jesusbonillam@ @otmail.com. ORCID ID: 0000-0001-9819-9318

${ }_{3}^{3}$ Enfermera. Egresada del Departamento de Enfermería, Facultad Ciencias de la Salud, Universidad del Cauca. Colombia. Correo electrónico: noryestefa@unicauca.edu.co. ORCID ID: 0000-0001-5954-2742

${ }^{4}$ Enfermera. Egresada del Departamento de Enfermería, Facultad Ciencias de la Salud, Universidad del Cauca. Colombia. Correo electrónico: auramilena@unicauca.edu.co. ORCID ID: 0000-0003-0554-2549
} 
Tipología: Artículo de Investigación.

Recibido: $03 / 07 / 2018$

Evaluado: $22 / 01 / 2019$

Aceptado: 08/02/2019

Disponible en línea: 10/02/2019

Como citar este artículo: Jojoa-Tobar, E; Bonilla-Muñoz, J.A; López-Guerrero, N.E \& Muñoz-Oviedo, A.M. (2019). Las Huellas del Conflicto Armado en la Salud Mental Colectiva. Jangwa Pana, 18 (1) 132 - 149. Doi: http://dx.doi.org/10.21676/16574923.2724

\section{Abstract}

Within the framework of the implementation process of the Integral Model of Health Care - MIAS, it is necessary to recognize and understand the impact that the armed conflict has had on mental health, especially in the most affected territories. This article is part of the research called "Collective mental health: impacts on people affected by armed conflict. Caldono, Cauca. 2017 "and provides elements for the development of interventions for the Promotion of Collective Mental Health, considering that peace, social justice, acceptable housing conditions, education and employment (WHO, 2004) are indispensable prerequisites for this. so that the identification and description of the effects that the armed conflict has generated on the family-community-territory relationship in the Municipality of Caldono, Cauca, constitute inputs for the development of interventions in a post-conflict scenario. The objective was to recognize the impact that the armed conflict has generated in the collective mental health of the indigenous and peasant community of the municipality of Caldono from the family-community-territory relationship. This qualitative phenomenological research, used for the collection of information observation and in-depth interviews with key informants. The information obtained was organized according to the dimensions of the social and cultural structure proposed in Madeleine Leininger's theory of the Rising Sun, identifying that the community of Caldono, due to its experiences with the armed conflict, has an impact on the collective mental health evidenced for invisible wounds of war; achieving in the collection of information recognize different problems that affect the community and the territory, including human suffering, social and territorial stigmatization and despair, among others. Likewise, other experiences that have contributed to strengthen their collective processes of organization, solidarity and resistance, as strategies for the conservation of life and the right to live in their territories, emerge around traumatic events.

Keywords: Collective Mental Health, armed conflict, impact, family, community and territory

\section{Introducción}

$\mathrm{E}$ 1 conflicto armado en Colombia inició hace seis décadas y sigue afectando de gran manera la población civil, ya sea directa o indirectamente; las víctimas identificadas por la Unidad para la Atención y Reparación Integral a las Víctimas (citada por Hewitt, et al, 2016) hasta octubre de 2013, son aproximadamente 5 845 002. Existe una afectación significativa en el Norte del Cauca, zona a la que pertenece el Municipio de Caldono, en el cual hasta el 2014 se han registrado diferentes tomas guerrilleras y hostigamientos, arrojando las siguientes cifras: 67 tomas guerrilleras en la cabecera municipal, 20 en el corregimiento de Siberia; tres atentados terroristas con carros bombas en la cabecera municipal y uno en el Corregimiento de Siberia, dando así un total de 267 hostigamientos en estas dos comunidades (Alcaldía de Caldono, 2017), lo que ha generado que el conflicto armado haya tenido un gran impacto tanto en la salud física, emocional y mental de familias y comunidades. 
Por otra parte, se ha evidenciado que las intervenciones comunitarias en salud mental no necesariamente plantean como partida procesos de capacitación de los equipos de salud y surgen en algunos casos de la intuición, de la improvisación (Arias, 2014), de las causas coyunturales o de la presencia de recursos humanos o económicos destinados a la atención psicosocial. En este mismo sentido, Tobón (2005) plantea que en Colombia se está frente a un panorama empírico de la promoción de la salud mental y de la prevención de las alteraciones mentales, en la que el uso indiscriminado de psicofármacos es la primera opción, desconociendo la multicausalidad y complejidad que acompañan estas problemáticas. Por tal razón, frente a los desafíos que se plantean desde el Modelo Integral de Atención en Salud -MIAS- y el rol de la enfermería comunitaria en el marco del posconflicto, se requiere generar evidencia que permita estimar las principales afectaciones que en la salud mental colectiva ha generado el conflicto armado, de tal manera que las acciones a realizar respondan a las problemáticas identificadas.

Respecto a la atención en salud mental en situaciones de conflicto armado, Rodríguez, De La Torre, y Miranda (2002), señalan que uno de los problemas identificados se encuentra relacionado con que la atención psiquiátrica solo beneficia a un número reducido de personas, desconociendo que la exposición a un evento traumático afecta a amplios grupos de la comunidad. En este sentido, es importante considerar que aún para brindar una atención individual el sistema de salud enfrenta grandes desafíos, toda vez que el recurso humano calificado se centra en las grandes ciudades, mientras que el mayor impacto del conflicto ha tenido como escenario los contextos rurales. Por tanto, si el acceso a la atención individual ya está limitado, más aún la atención a la salud mental familiar y colectiva, la cual se ha visto afectada a lo largo del desarrollo del conflicto armado colombiano; lo anterior plantea la necesidad de descentralizar y despatologizar la salud mental.
En el contexto latinoamericano Rodríguez et al. (2002) indican que, sobre este tema no hay suficientes estudios que evidencien el impacto de la salud mental en poblaciones desplazadas, con excepción de investigaciones realizadas en Honduras y Guatemala, no obstante, consideran que durante los conflictos armados tanto la salud individual como colectiva se ve comprometida en el corto y largo plazo.

En Colombia los estudios con población adulta víctima del conflicto armado, reportan comorbilidad entre Trastorno de Estrés postraumático -TEPT-, ansiedad y depresión, según lo encontrado por Bell et al., (citado por Hewitt et al., 2016). Por su parte Londoño, Romero y Casas, (citado por Hewitt et al., 2016), reportaron una prevalencia de síntomas de ansiedad entre el $25.7 \%$ al $32.5 \%$, de trastorno de somatización entre $61 \%$ y $73.8 \%$, abuso de alcohol entre $23.8 \%$ y $38.1 \%$ y trastornos de la alimentación entre $4.7 \%$ y $11.9 \%$.

De modo, que en estas últimas se han centrado principalmente la identificación del impacto individual, mientras que las afectaciones a nivel familiar y colectivo han sido poco abordadas desde el campo investigativo, aspecto que cobra trascendental importancia considerando que el conflicto armado ha tenido como principal escenario contextos rurales en donde los lazos familiares y comunitarios son muy estrechos y en donde el territorio cobra especial significancia por ser el espacio donde transcurre la vida. Es por ello que, Rodríguez, et al. (2002) planteen que se hace necesario considerar otros fenómenos que emergen en contextos de conflicto armado como el miedo, la aflicción, el desorden social, la violencia y el consumo de sustancias psicoactivas.

Por lo tanto, reconocer y comprender el impacto que sobre la salud mental ha ejercido el conflicto armado desde las relaciones familia-comunidadterritorio, contribuye a disponer de elementos para diseñar e implementar planes integrales de cuidado de la salud que incluyen; atenciones y acciones individuales y colectivas para 
promover la salud, prevenir, manejar, rehabilitar y paliar la enfermedad (Zurro y Solà, 2011). Por su parte el MIAS reconoce a las familias y comunidades como sujetos de atención en salud, lo que implica la necesidad de desarrollar intervenciones de Promoción de la Salud Mental Colectiva a partir del fortalecimiento del diálogo de saberes entre la academia, las familias y las comunidades entorno a problemáticas como las abordadas en esta investigación.

Cabe resaltar qué por la complejidad, amplitud y profundidad de los hallazgos encontrados en la presente investigación, este artículo se ocupará de dar respuesta al objetivo específico de determinar el impacto que el conflicto armado ha generado en la salud mental colectiva, respecto a la comunidad y su construcción de territorio.

\section{Materiales y métodos}

Esta es una investigación cualitativa fenomenológica, donde se busca conocer situaciones, momentos de la vida y experiencias vividas por familias y comunidades afectadas por el conflicto armado; la población de estudio fue la comunidad del municipio de Caldono (Cauca). Para el desarrollo de la investigación se sostuvieron reuniones previas con autoridades locales y organizaciones sociales, quienes apoyaron la identificación de informantes culturales y líderes comunitarios, que por su trayectoria en el municipio y su rol en los procesos de resistencia civil o su condición de víctima del conflicto armado podían aportar en este proceso. Los criterios de inclusión para los participantes fueron: ser mayor de 18 años y haber vivido en el Municipio de Caldono (Cauca) por más de diez años.

La recolección de información se realizó utilizando cuatro instrumentos diseñados por los investigadores: guía para observación del lugar, que fue utilizada durante los recorridos por la zona urbana y rural afectada por las incursiones armadas; guía de observación de los sujetos, descripción del lenguaje no verbal durante los relatos; guía para las entrevistas a profundidad con informantes claves, las cuales fueron grabadas; y fotografías.

Para las entrevistas, los participantes firmaron un consentimiento informado, garantizando la confidencialidad de la información obtenida en el desarrollo de la investigación, la integridad, la protección del bienestar de los sujetos y la seguridad de la información aportada, por tal razón las referencias de las comunicaciones personales solo fueron identificadas con los números y fechas de las entrevistas realizadas. Por lo sensible de la información obtenida, los investigadores se abstienen de dar los nombres y apellidos de las personas entrevistadas, compromiso que fue explícito en el consentimiento informado. Se realizaron nueve entrevistas a profundidad, alcanzando la saturación de información, las cuales fueron trascritas para luego de ser analizadas y proceder a definir las categorías para su análisis.

Los resultados se clasificaron utilizando los factores propuestos en la teoría del Sol Naciente de Madeleine Leininger, representando componentes de la estructura social y los factores de la concepción del mundo que influyen en los cuidados y la salud.

\section{Declaración de aspectos éticos}

Esta investigación se basa en los principios estipulados en CIOMS/82 - 2002 en lo referente a la justificación ética y validez científica de la investigación biomédica en seres humanos, donde se pone de manifiesto que esta radica en la expectativa de descubrir nuevas formas de beneficiar la salud de las personas. Desde esta perspectiva, los investigadores consideran que esta investigación contribuye a sensibilizar al personal de salud sobre el impacto que ha tenido el conflicto armado en la Salud Mental Colectiva $\mathrm{y}$ a reconocer los recursos que han desarrollado para afrontar dicho impacto, de tal manera que estos sean utilizados para el desarrollo de intervenciones psicosociales en la promoción de la salud mental colectiva y en los procesos de incorporación de la población desmovilizada a la vida civil. 
Así mismo, esta investigación considera la resolución 008430 de 4 de octubre de 1993, en la que se establece las conductas científicas, técnicas y administrativas para la investigación en salud, TITULO II: de la Investigación en Seres Humanos, Capítulo I: de los Aspectos Éticos de la Investigación en Seres Humanos: "en toda investigación en el que ser humano sea objeto de estudio, deberá prevalecer el criterio del respeto a la dignidad y la protección de los derechos y bienestar" y en conjunto con el Artículo 11, la investigación se considera sin riesgo, ya que "no se realiza ninguna intervención o modificación intencionada de las variables biológicas, fisiológicas, psicológicas o sociales de los individuos" (Ministerio de Salud y Protección Social, 1993).

Para la realización de esta investigación, se tuvo en cuenta principios éticos de autonomía, beneficencia, no maleficencia y justicia, participando del estudio solo las personas que accedieron voluntariamente al mismo.

Se garantizó el respeto al derecho de proteger la integridad, se tomarán toda clase de precauciones para resguardar la intimidad de los individuos y la confidencialidad de la información obtenida, todo esto estipulado en el consentimiento informado.

\section{Resultados}

\section{Un día después de la guerra...}

Aunque el municipio de Caldono fue uno de los escenarios estratégicos desde donde se libraron las confrontaciones entre actores armados ilegales y fuerza pública, desde el año 2012 no se registran en su territorio acciones armadas, sin embargo, en la memoria colectiva están vivos los recuerdos de los hechos violentos ocurridos en su territorio y que marcaron la vida de sus habitantes.

El conflicto armado dejó una huella imborrable a través de hechos como el desplazamiento colectivo, que fue uno de los principales acontecimientos del cual se desencadenan diversas afectaciones sobre la salud mental de la comunidad, debido que poco a poco, toma tras toma, logró fragmentar a una comunidad que cansada de convivir con una guerra que no era de ellos, solo tuvo una opción; abandonar sus hogares, territorio, amigos y familias en busca de una posibilidad de conservar su vida y la de sus seres queridos.

Por otro lado, existía un entorno no menos alentador para la población que decidió quedarse en su territorio, como respuesta del Estado se obtuvo la militarización de la vida civil que trajo consigo no solo nuevos conflictos, sino que generó otros problemas en la comunidad como el aumento de embarazos no planeados y el consumo de sustancias psicoactivas. Así mismo, se seguían enfrentando diariamente a sucesos como muertes selectivas, desapariciones y reclutamiento forzado por parte de los grupos armados ilegales, que sin escrúpulos desintegraban familias, o promovían la desesperanza amenazando a las personas de la comunidad que buscaban defender sus derechos, se evidenció entonces persecuciones a líderes sociales y funcionarios públicos que se atrevían a hacerles frente $y$ repudiar sus acciones violentas.

Las incursiones guerrilleras se convirtieron progresivamente en algo cotidiano, cambiaron totalmente la dinámica familiar y comunitaria de este territorio, debido a que todas sus actividades se desarrollaban alrededor de acciones de precaución o preparación para cuando iniciaran con o sin previo aviso. Estos hechos violentos estaban acompañados del uso de armas no convencionales por parte de los actores armados ilegales y de artillería aérea por parte de las fuerzas del Estado, lo que conllevó a vivenciar situaciones cada vez más complejas. A esto se le sumó la utilización de espacios públicos como campamentos y trincheras de guerra, lo cual terminó por invadir a toda la comunidad con un miedo y zozobra que solo los convirtió en espectadores de primera fila de las atrocidades que traía consigo la guerra y que solo dejaba a su 
paso recordatorios de las batallas vividas que no permitían ser olvidadas; claro ejemplo de esto, fue la afectación y pérdida de la infraestructura familiar y comunitaria que quedaba reducida a escombros.

No obstante, al terminar el conflicto en esta comunidad aún quedan despojos de la guerra que continúa generando peligro a la población; las municiones sin explotar (MUSE) esparcidas a lo largo del territorio no solo generan discapacidades físicas en quienes accidentalmente las activan, sino también una sensación permanente de incertidumbre al caminar por el territorio.

Sin duda, la exposición permanente de familias y comunidades a estos factores estresores que afectaron sus dinámicas cotidianas y la vida en el territorio, comprometió la salud mental colectiva de diferentes maneras, las cuales se sintetizan en la siguiente ilustración (Figura 1) a través de la cual se presentan las categorías y subcategorías definidas en esta investigación.

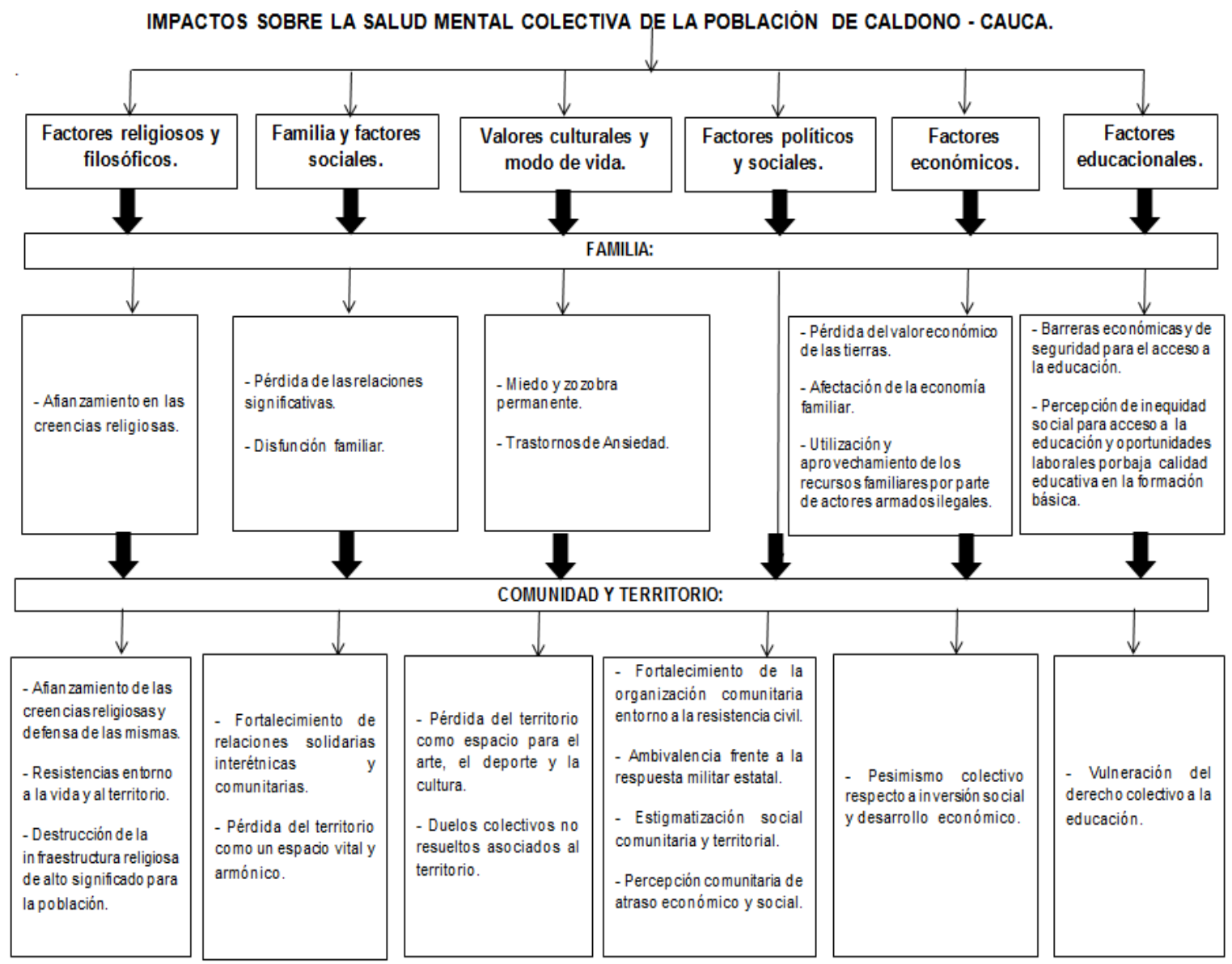

Figura 1. Categorización de resultados. Impactos sobre la salud mental colectiva de la población de Caldono - Cauca. 2017. Fuente: Elaboración propia.

Considerando la amplitud, profundidad y complejidad de los hallazgos que arrojó esta investigación; a continuación, se presentarán los resultados relacionados con el impacto que el conflicto armado ha generado en la salud mental colectiva, respecto a la comunidad y su construcción de territorio. 


\section{El fantasma de la guerra presente en el territorio y la comunidad}

En una guerra en la que el territorio toma un papel protagónico, tanto desde el punto de vista espacial como desde la connotación que la comunidad le da a éste desde sus prácticas y creencias culturales, se logró identificar que hay un gran impacto en la salud mental colectiva debido a que muchos de sus lugares significativos (viviendas, iglesia, escuela, colegios, comedores escolares, fincas) sufrieron afectaciones por el conflicto armado que han generado una re-significación de los mismos hacia una connotación negativa, pues evocan hechos muy dolorosos. Algunas estructuras han sido reconstruidas, pero otras se convierten en testimonios crudos de hechos violentos que mantienen en la memoria colectiva un pasado que marcará para siempre su historia.

Las huellas del conflicto armado en la salud mental colectiva en relación con el territorio y la comunidad se presentan, considerando las dimensiones de la estructura social y cultural propuestas por Madeline Leininger y utilizadas en esta investigación, como categorías para el análisis de la información obtenida.

\section{Factores religiosos y filosóficos}

Ante los numerosos ataques por parte del grupo armado ilegal, la comunidad afianzó sus creencias tanto religiosas como espirituales desde sus saberes ancestrales, brindando no solo esperanza y "protección" a la comunidad, sino también diálogos interreligiosos que contribuyeron al fortalecimiento de los esfuerzos comunitarios por garantizar la convivencia y el cese de las hostilidades; así lo relata un líder comunitario: "Logré unir las iglesias en Caldono, las iglesias evangélicas, los pastores, el cura, las autoridades, invité a la guerrilla, invité los cabildos, la policía, el ejército para hablar de paz porque no podíamos seguir así" (No. 1, comunicación personal, 24 de mayo de 2017).

El miedo hacía parte del diario vivir de la comunidad de Caldono, sin embargo, cansados de que la guerra alterara de tal manera sus dinámicas económicas, sociales y comunitarias, y que se vulnerara su derecho a ocupar el territorio como espacio vital; con valentía se armaron resistencias entorno a la defensa de la vida y el territorio, como única posibilidad de sobrevivencia. Las resistencias fueron movilizaciones pacíficas, pero masivas, mediante las cuales y a través de parlantes, banderas, gritos y bloqueo de las entradas al pueblo, la comunidad impidió que los actores armados ilegales ingresaran al casco urbano y siguieran causando más daño. La iglesia católica apoyó estas movilizaciones y con ello lograron frenar las incursiones guerrilleras. Así lo expresa una de las personas entrevistadas:

Las personas que se quedaron aquí no tenían otras posibilidades y le hicieron frente a toda esa ola de violencia donde nacieron las famosas resistencias teniendo el coraje y la valentía para sacar adelante las cosas y defender su territorio (No. 2, comunicación personal, 24 de mayo de 2017).

El hastío de la guerra es expresado por las acciones de resistencia civil que se recuerdan así:

En Caldono en una de las tomas me cuentan que ya después de varias tomas [ehh] llegó un momento en donde dijo la gente no más, no más, no más y yo recuerdo que estuve ahora un año allá y ellos hicieron la conmemoración de los 14 o 15 años de resistencia civil, donde ellos en medio de las balaceras, en medio pues de las bombas y todo eso salieron, salieron con el sacerdote a decir no más, no más, pare la violencia, no tiene que ver nada con nosotros, ¿Por qué nos matan a nosotros?, sacaron banderas y ahí hicieron la primera resistencia (No. 1, comunicación personal, 24 de mayo de 2017).

El templo católico del corregimiento de Siberia, debido a su ubicación, era vulnerable a los atentados y hostigamientos que realizaban en el 
municipio, en una de las tantas tomas armadas se destruyó gran parte de la infraestructura, afectando a la comunidad de una forma especialmente significativa, toda vez que el hecho ocurrió en medio de la celebración de una fiesta patronal, que es de especial significancia en una comunidad rural de mayoría católica. "En una de las tomas se tumbó el techo, toda la iglesia la tumbaron y quedaron simplemente las paredes como tal. Fue una de las tomas más dañinas a la vez que impactó como tal a la comunidad" (No. 3, comunicación personal, 24 de mayo de 2017).

Para estos territorios las festividades religiosas son oportunidades de encuentro entre las comunidades rurales y del casco urbano, de retorno para personas que habitan en las grandes ciudades y son un símbolo de unidad entorno a sus creencias religiosas, por tal razón, el hecho de que se haya afectado esta estructura tuvo un gran impacto en la comunidad, tal como se evidencia en el siguiente relato:

Huyyyy pues al otro día que miramos la iglesia eso lloraba todo el mundo, eso era impresionante, era ver mujeres, niños llorando, viendo la iglesia, el Padre también, entonces pues se esperaba una fiesta bien bonita y nos cogió fue esa, esa... inclusive esa tarde se hizo la eucaristía campal, acá en el parque porque pues ya no teníamos iglesia. Ehhhhh y claro, eso psicológicamente todo el mundo mal, estábamos mal (No. 3, comunicación personal, 24 de mayo de 2017).

La observación de las ruinas que aún se encuentran cerca de la Iglesia y el lugar que ocupaba el puesto de policía, permite evidenciar la proximidad de estas estructuras.

\section{Familia y factores sociales}

Frente al caos y el miedo reinante, el fortalecimiento de las relaciones solidarias interétnicas y comunitarias, se convirtieron en el principal soporte para las crisis; las comunidades vecinas fueron el refugio para la comunidad de
Caldono, estas le brindaban ayuda tanto de vivienda como de alimentación, especialmente durante las incursiones guerrilleras. Además, la comunidad era solidaria con las familias afectadas por los daños en la estructura de sus casas, secuestros, asesinatos o reclutamientos forzados. Cuando se presentaba un atentado terrorista en los centros poblados, los habitantes afectados se dirigían a las veredas cercanas buscando refugio. Los informantes culturales lo relatan así:

Yo aprovecho para decirle a la gente de la Venta, de Campo Alegre que les agradezco mucho por la hospitalidad que siempre nos dieron porque el llegar sin nada y llegar allá que lo atendieran con desayuno, almuerzo y todo eso es una bendición muy importante para el pueblo de Caldono (No. 2, comunicación personal, 24 de mayo de 2017).

Aun cuando la población en general estaba en condiciones de pobreza, la solidaridad se fortaleció como lo expresa otro de los entrevistados: "La comunidad decía vea, esta familia hay que regalarle algo así sea una libra de arroz, una panela o como ayudarlos" (No. 4, comunicación personal, 24 de mayo de 2017).

A causa de los diferentes hostigamientos y los daños subsecuentes en la infraestructura, se fueron perdiendo espacios vitales y armónicos en su territorio, como sus lugares de refugio, y las familias se quedaban sin protección, por lo cual se requería ir cada vez más lejos para proteger sus vidas y las de su familia. Esto se evidencia en uno de los relatos:

La segunda toma era en el barrio donde yo vivía, era la única casa que tenía una plancha, ahí nos amontonábamos todos los del barrio, era como más chévere porque uno estando entre varios se sentía menos miedo, pero en la tercera toma, toda la plancha se llenó de guerrilleros y es horrible porque imagínense que ya uno no tiene sitio seguro (No. 2, comunicación personal, 24 de mayo de 2017). 


\section{Valores culturales y modo de vida: Pérdida del territorio como espacio para el arte, el deporte y la cultura}

Los investigadores evidenciaron, a través de los relatos, que la comunidad contaba con diferentes espacios públicos para el servicio y beneficio de sus pobladores, sin embargo, a medida que los grupos armados llegaban se fueron perdiendo espacios para el arte, el deporte y la cultura. La ocupación de estos espacios por campamentos improvisados convirtió en nula la vida social y al pueblo en un fantasma nocturno. $\mathrm{Y}$ que las personas lo expresan así:

El polideportivo era donde se hacían los campeonatos, la vida nocturna se acabó, no se hacían partidos, no se hacía nada, se acabaron los espacios de encuentro y recreación... En las noches se practicaba danza, teatro, música y cuando llegó esa época se acabó todo... Hasta ahora, todavía no hemos podido recuperar eso (No. 3, comunicación personal, 24 de mayo de 2017).

Existen duelos colectivos no resueltos asociados al territorio. La violencia dejó una huella en la comunidad que a través del tiempo no ha sanado, al observar los lugares que han utilizado los actores de la violencia se evidencia que se generan sentimientos de nostalgia y dolor. Cada paso que se da en el territorio guarda las huellas imborrables de la crueldad del conflicto, las ruinas aún presentes llevan a la evocación de hechos dolorosos, de heridas emocionales colectivas que aún no se han cerrado. Al caminar por el parque principal uno de los informantes recuerda:

Aquí perdimos un concejal, el 17 de diciembre de 2010, ahí en la puerta de la iglesia lo mataron, o sea fueron tan descarados que le hicieron una llamada y uno pues...bueno ya cuando le toca, salió a contestar la llamada y ahí lo mataron (No. 2, comunicación personal, 24 de mayo de 2017).

\section{Factores políticos y sociales}

La comunidad del Municipio de Caldono no solo fue víctima de grupos armados ilegales sino también de las fuerzas militares, el fortalecimiento de las políticas de seguridad significó un incremento del pie de fuerza, armamento más sofisticado e incremento de aeronaves de combate; su llegada generó doble efecto, por un lado, protegían a la población, pero por otro ocasionaban gran temor y daños en la infraestructura, toda vez que el apoyo aéreo afectaba también a la población civil. Uno de los participantes recuerda estas vivencias así:

Al enviar apoyo era peor porque llegaban los helicópteros, los aviones y entonces, uno ya no sabía de quién defenderse, si de los tatucos, de los cilindros, de las balas de la guerrilla, de los explosivos o las balas del avión fantasma (No. 2, comunicación personal, 24 de mayo de 2017).

Los relatos dan cuenta de la estigmatización de la comunidad y su territorio; por ser el escenario del conflicto, la sociedad en general asumió que por el solo hecho de proceder de las denominadas "zonas rojas" se era perteneciente a los grupos armados ilegales, por otra parte, se prevenía a funcionarios y demás personas de abstenerse de ir a las mismas, situaciones que volvían cada vez más críticas para quienes salían, pero también para quienes resistieron en el territorio. Así lo refieren los participantes: "Cuando uno se iba a las universidades o a los institutos, o salía de acá del municipio le preguntaban ¿Usted de donde es?... de Caldono... ¡Es guerrillero!... y muchas veces eso le cerraba a uno espacios" (No. 7, comunicación personal, 07 de octubre de 2017).

La posibilidad de contar con recursos humanos calificados y con continuidad en el municipio también se vio comprometida. Uno de los participantes relata respecto a la notificación de su traslado a este municipio lo siguiente: "Cuando me mandaron a Caldono decían: ¡Nooo pero Caldono! ¡Zona roja, que miedo Dios mío!, 
cómo se va a ir para allá, ¿Por qué lo mandaron por allá?" (No. 1, comunicación personal, 24 de mayo de 2017).

La comunidad de Caldono percibió también como un atraso económico y social, el retiro de la única entidad financiera del municipio, tras la ola de violencia y ataques directos a esta entidad financiera. Uno de los participantes lo refiere así: "Contábamos con banco Agrario, con los hostigamientos lo dañaron y los funcionarios se fueron junto con la policía porque ya no aguantaban" (No. 3, comunicación personal, 24 de mayo de 2017).

\section{Factores económicos}

Los relatos permitieron a los investigadores encontrar los siguientes impactos: Las tierras se desvalorizaron, a causa de los constantes hostigamientos y la contaminación del territorio por el uso de armas no convencionales; el principal capital de estas comunidades era la tierra y su principal actividad económica era la agricultura, pero los constantes hostigamientos no les permitían desarrollar sus actividades. El comercio también se vio afectado debido a la proximidad con la estación de policía, pues aunque los ataques iban dirigidos a la estación, estos no llegaban a su objetivo sino que caían en los establecimientos comerciales vecinos, afectando la infraestructura comercial y generando un pesimismo colectivo respecto a inversión social y desarrollo económico, dado que los potenciales inversionistas, comerciantes o propietarios de las tierras, no desarrollaron proyectos por miedo a perder sus recursos, cultivos y/o infraestructuras.

Evocando estas vivencias uno de los participantes relata: "El valor de la tierra se afectó grandemente, en ese tiempo por una finca le ofrecían solo 2 millones o millón y medio, porque decían que ni regalado compraban" (No. 3, comunicación personal, 24 de mayo de 2017). La pobre inversión estatal en vías y en proyectos productivos tuvieron también su impacto en la ya frágil economía de la región, es así como uno de los participantes señala: "Las personas debido al estado de las vías no puede explotar sus pequeñas parcelas, ya sea porque no hay progreso o proyectos desde el gobierno" (No. 1, comunicación personal, 24 de mayo de 2017).

Al ser un pueblo pequeño todo el comercio se localizaba en un solo sector y por ende la afectación de las intervenciones armadas fue evidente, al respecto otro informante refiere: "Donde era la policía, también quedaba la calle del comercio, ese era el entorno de todos los negocios, con las tomas todas esas tiendas volaron" (No. 5, comunicación personal, 07 de octubre de 2017). Las pérdidas económicas en la población civil son aún hoy evidentes, al recorrer el pueblo se pueden encontrar viviendas destruidas cuyas familias paradójicamente tienen deudas exorbitantes por servicios públicos. La siguiente fotografía (Imagen 1) muestra las ruinas de lo que en su tiempo era la casa más bonita del pueblo. 


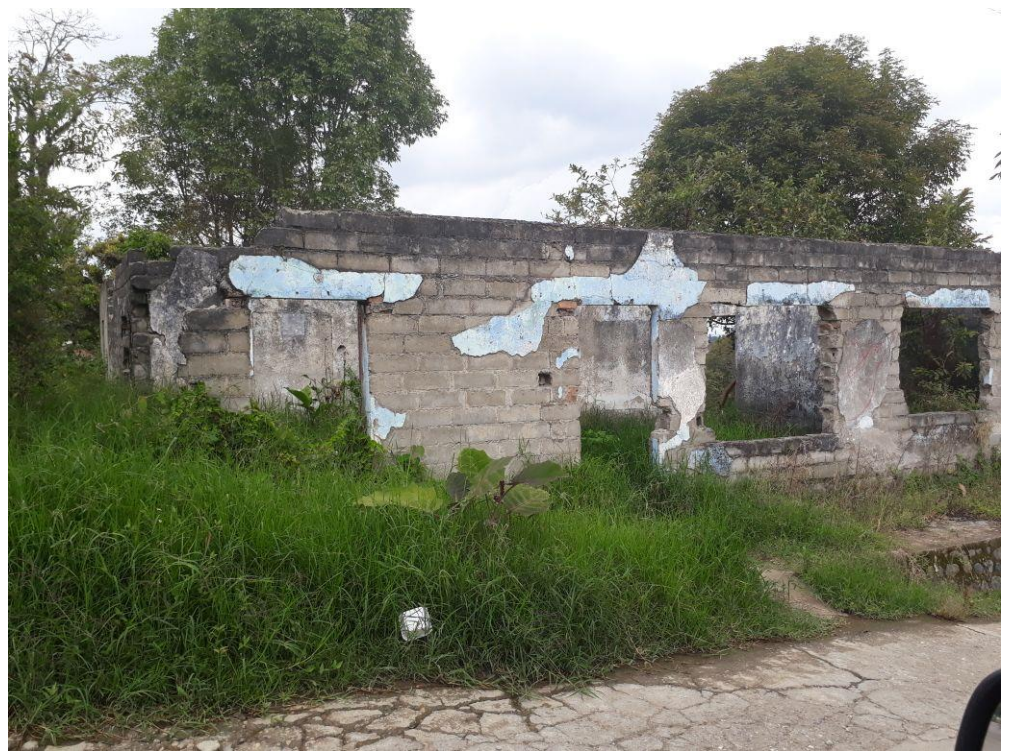

Imagen 1: Ruinas de una vivienda familiar. Caldono, Cauca. 2017

\section{Factores educacionales}

Las incursiones armadas afectaron principalmente la infraestructura de las diferentes instituciones educativas donde se evidenció la vulneración del derecho colectivo a la educación; los participantes perciben que los cambios en el calendario académico, la frecuente suspensión de clases por enfrentamientos que se realizaban durante el día, la alta rotación de profesores, el hacinamiento, los cambios de horario para poder utilizar la infraestructura que lograba mantenerse en pie, el estrés previo y posterior a los ataques en estudiantes, profesores y padres de familia por la amenaza permanente de enfrentamientos, la decisión de los padres de familia de tener que enviar a sus hijos a instituciones educativas localizadas fuera del pueblo, entre otras consecuencias del conflicto armado en el sector educativo, generaron un impacto negativo en la calidad de la educación en comparación con estudiantes de otros municipios o de quienes habitaban en las ciudades, lo que implicaba menores oportunidades de acceder a la educación superior o a oportunidades de empleo, considerando que también hubo impacto en la deserción escolar.

Las instituciones educativas fueron muy afectadas considerando su proximidad a las instalaciones policiales y en otros casos porque al ser destruido el comando de policía, estas eran ocupadas por la fuerza pública. Al respecto este es el relato de uno de los participantes: "Destruyeron todos los colegios, solo quedó uno: el colegio Susana López de Vivas, allá tocó organizar tres jornadas: mañana, tarde y noche, para poder que no perdieran clases, fue difícil recuperar esas instituciones" (No. 2, comunicación personal, 24 de mayo de 2017). Otro participante refiere: "Los niños tenían que estudiar en una bodega porque destruyeron la escuela, la volvieron nada" (No. 5, comunicación personal, 07 de octubre de 2017).

Las ruinas de lo que era una de las principales instituciones educativas del municipio son ahora trincheras para la fuerza pública, tal como puede apreciarse en la siguiente fotografía: 


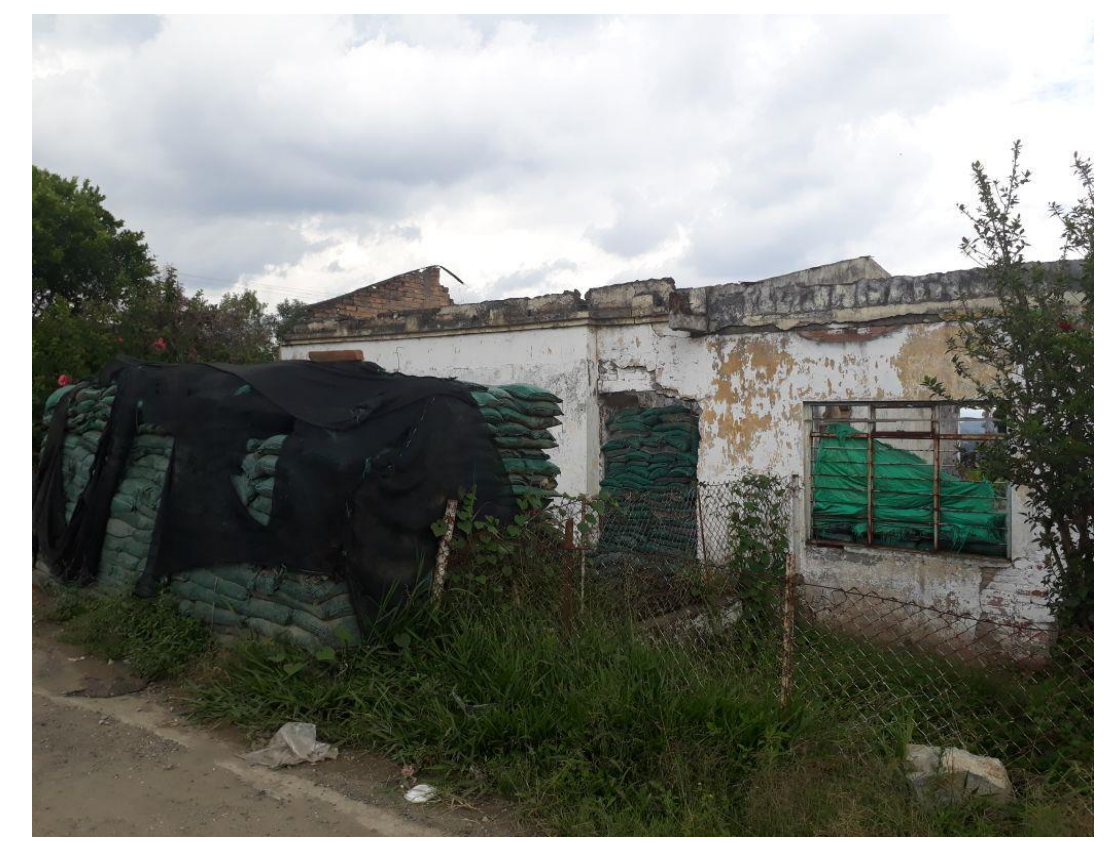

Imagen 2: Ruinas del Colegio Madre Laura. Caldono, Cauca. 2017

La infraestructura complementaria a las actividades educativas, también se vio afectada, una de las afectaciones más sensibles fue la destrucción del restaurante escolar. La siguiente fotografía revela el estado actual:

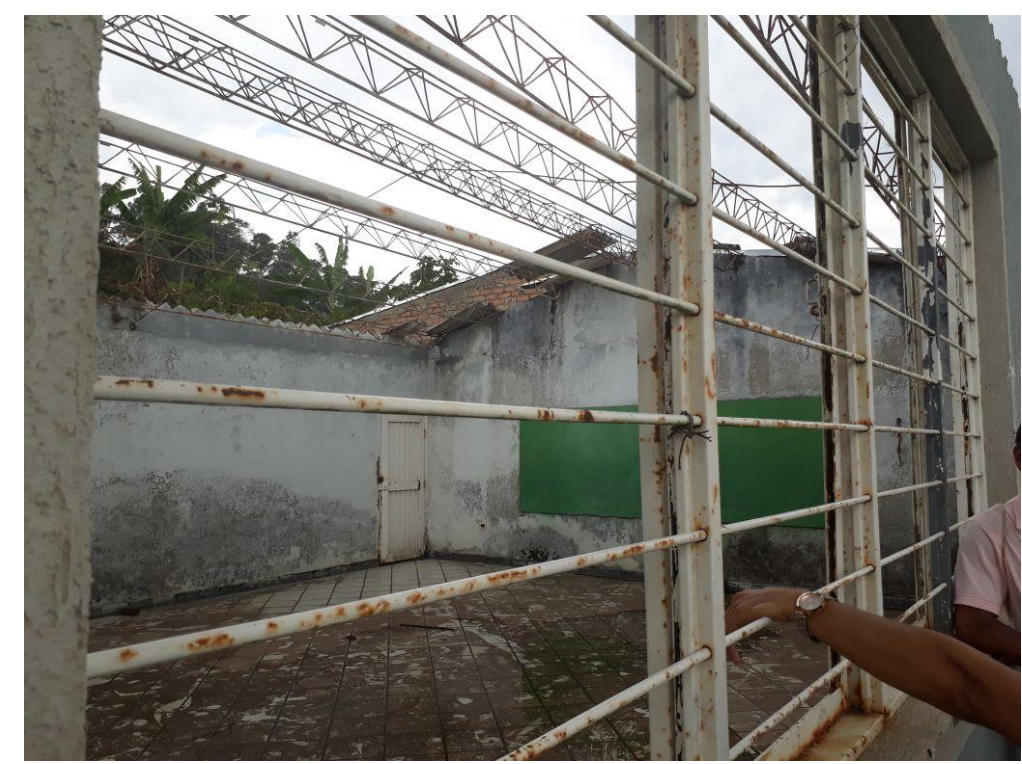

Imagen 3: Ruinas del Comedor Escolar del Colegio Madre Laura. Caldono, Cauca. 2017 


\section{DISCUSIÓN}

\section{El impacto del conflicto en la salud mental colectiva: Una fractura no consolidada}

La familia, la comunidad y el territorio son claves al momento de reconocer los impactos que ha generado el conflicto armado en la Salud mental colectiva, al respecto, Gómez, Tamayo y Buitrago (2016) consideran que el impacto de la violencia en Colombia ha comprometido la estabilidad y la estructura social conllevando a un deterioro de la calidad de vida, la salud física y mental de la población colombiana. Estas repercusiones son muy evidentes en la población de estudio reflejado en; el desarraigo de su territorio, la desesperanza ante un futuro incierto carente de oportunidades educativas, económicas y de inversión social, la estigmatización de su territorio y de su gente, la fractura de la institucionalidad, las amenazas a sus líderes sociales y la incertidumbre permanente de una amenaza real para la vida con pocas posibilidades de afrontamiento.

Estas vivencias aún no han sido sanadas y siguen doliendo en el imaginario colectivo, por ello, al recorrer el territorio y aún presenciar las ruinas de lo que fueron las instituciones educativas o las viviendas de muchas familias, se evocan dolorosamente los hechos que las precedieron, dolor que se incrementa al evidenciar que, aún en un periodo de pos-acuerdo, la respuesta estatal aún no logra reparar colectivamente a esta comunidad mediante la reconstrucción de su infraestructura, por lo que esta se convierte es testigo mudo de una fractura entre un antes y un después de las tragedias ocurridas.

La estigmatización de su territorio como "zona roja" y de sus pobladores como "guerrilleros", ha significado una re-victimización social y estatal que ha dejado huellas; que durante el conflicto activo los privó de oportunidades personales $\mathrm{y}$, que, desde lo colectivo, limitaron la llegada de recursos humanos de calidad a las instituciones estatales del municipio, el acceso oportuno y de calidad a bienes y servicios.
Estos hallazgos llevan a proponer que la salud mental colectiva debería ser entendida como la relación armónica de la familia-comunidadterritorio, toda vez que, de las relaciones significativas, recíprocas y saludables que se establezcan, entre ellos, dependerá el bienestar emocional, mental y espiritual de familias y comunidades que a su vez asumen el territorio como un espacio vital.

Esta iniciativa se sustenta desde el concepto de la geografía del cuidado que considera que los territorios se entienden no sólo como contenedores físicos de actividades humanas, sino como un escenario donde se tejen interacciones complejas de características físicas y sociales, las cuales contienen sentimientos, identidades y simbolismos, tanto en las dimensiones individuales como comunitarias, además, los territorios dan significado por medio de sus espacios sociales, a actividades, rituales e interacciones de cuidado (Pardo y González, 2007). Por tanto, el cuidado de la salud mental, en contextos donde el territorio fue convertido en campo de guerra, amerita el reconocimiento y comprensión de cómo el conflicto armado comprometió las relaciones de familias y comunidades con su territorio, de tal manera que las intervenciones de promoción de la salud mental colectiva, incorporen elementos que trasciendan el abordaje individual que ha prevalecido cuando de intervenciones psicosociales se trata.

Por tanto, el desarrollo de intervenciones en salud mental colectiva requiere que los equipos de salud dispongan de información del cómo se ha ejercido el poder de los distintos actores sociales sobre el territorio, la construcción histórica de la territorialización y de la producción económica, así como de las formas e hitos organizativos de sus comunidades, toda vez que estas situaciones han contribuido a generar procesos de autocuidado y reparación colectiva que no pueden ser desconocidos. Así mismo, han posibilitado la ocupación del territorio por distintos actores en ocasiones como producto de disputas, en otras por acuerdos y 
esto influye directamente en las dinámicas comunitarias, las cuales pueden verse o fraccionadas o fortalecidas en estos procesos.

Para el contexto estudiado, por ejemplo, es claro como la comunidad se siente fortalecida y empoderada al lograr por medio de las acciones de resistencia "recuperar" su territorio. Foucault, (citado por Arias, 2014) considera que la resistencia conlleva una condición afirmativa más que defensiva, pues posibilita la creación de nuevas maneras de vivir y relacionarse consigo mismo y con los otros en un contexto de relaciones asimétricas de poder, en el que se pretende alterar y transformar dichas asimetrías.

En tal sentido el abordaje de la salud mental colectiva implica una construcción "con" y "para" las comunidades afectadas por el conflicto armado, de tal manera que se propicien:

Intervenciones socio-terapéuticas cimentadas ética y políticamente en la solidaridad, la confianza y la reconciliación que conversen y cuestionen los modelos tradicionales vinculados al estricto seguimiento de lineamientos institucionales, para avanzar en la formación democrática y de participación ciudadana de las víctimas y excombatientes desde lo individual, lo familiar, lo colectivo y lo comunitario (Torres, 2017).

Este abordaje permitiría alcanzar el objetivo propuesto en el Plan Decenal de Salud Pública desde el componente de Promoción de la Salud Mental y la Convivencia, el cual busca intervenir los determinantes psicosociales de la salud y calidad de vida en poblaciones víctimas del conflicto armado mediante la implementación de acciones transectoriales (Minsalud, 2013).

\section{La solidaridad: Lo que vale la pena recordar}

Aunque para los participantes resulta doloroso evocar las dificultades generadas por el conflicto en relación a los mecanismos de protección como el desplazamiento temporal, cargando con lo poco o nada que podían tomar en el corto plazo del que disponían antes de cada confrontación, es muy significativo encontrar como los actores comunitarios reconocen las muestras de solidaridad de comunidades cercanas a donde llegaban buscando refugio y en donde eran acogidas con techo y comida.

Disponer a cualquier hora de un lugar seguro, bien sea en casas cercanas que por infraestructura o ubicación eran consideradas más seguras, constituía de alguna manera una luz de esperanza en medio de situaciones caóticas. Osorio (2001) considera que, si bien, estas estrategias de solidaridad pueden ser vistas como algo de muy poco alcance, en el mediano y largo plazo, constituyen una fuerza importante para la supervivencia de las familias y la construcción de nuevas redes sociales.

La solidaridad emerge en este contexto como un valor comunitario que, en estos casos, significó la protección de la integridad de quienes buscaron refugio en otras familias o comunidades cercanas, por su parte, quienes fueron acogidos en tan difíciles circunstancias manifiestan su gratitud, aun cuando ya ha pasado el tiempo. En este sentido, Bang (2014) considera que las prácticas/acciones de promoción de salud mental comunitaria son aquellas que contribuyen a la transformación de las relaciones comunitarias hacia vínculos solidarios y la participación hacia la constitución de la propia comunidad como sujeto activo de transformación de sus realidades. Por ello, estas experiencias de reconocimiento y fortalecimiento de los valores comunitarios se convierten en el punto de partida para garantizar una "acción sin daño", en el marco de las intervenciones psicosociales en un periodo de posconflicto/ posacuerdo.

\section{La resistencia: Estrategia para la defensa de la vida y el territorio}

La intensidad del conflicto, los impactos generados en la economía, la educación, las formas de vida y de todas las dinámicas 
comunitarias, pero sobre todo la muerte, desaparición, reclutamiento y amenazas a la población civil, transformaron el miedo en valentía y esta comunidad encontró en la resistencia civil, la única estrategia para la defensa de la vida y del territorio. Sin embrago, aún se preguntan cómo es que ellos pretendían que con simples banderas, gritos, bancas y palos a la entrada del pueblo y formando un cordón humano (Pozzi y Tansini, 2011) lograron parar en repetidas ocasiones el ingreso de la guerrilla al pueblo, pero es que aunque comenzaron unos pocos, cada vez se sumaron más y más, a tal punto que a la guerrilla se le hizo imposible tomarse el pueblo en medio de civiles que solo tenían como arma el primer trozo de tela blanco que encontraron y como munición sus gritos de cese a la violencia.

El rol de la iglesia católica y de su líder espiritual, fueron decisivos en este proceso. Ante la iniciativa de la comunidad, la campana de la iglesia y la voz del sacerdote, llamando por un altoparlante a apoyar esta iniciativa comunitaria, llenó de fe y fortaleza a todo un pueblo que dejó de esconderse y que con valentía salió a defender su territorio. Frente a estas formas de defensa comunitaria, Arias (2014) señala que estas acciones sumadas al aprendizaje histórico de experiencias de trabajo colaborativo y de movilización social, se convierten en un antecedente que permite que aún se continúe defendiendo el derecho a habitar su territorio, cultivar y trabajar la tierra que conocen, sienten propia y que dota de sentido a sus vidas.

Y es que desde su relación con el territorio estas comunidades dan sentido a sus formas de relacionamiento con la familia, sus vecinos, sus prácticas económicas, culturales, espirituales y de salud. El territorio hace parte de su historia personal, familiar y comunitaria, por tanto, defender este espacio cobra una trascendencia vital. El logro de esta comunidad animó a otras $\mathrm{y}$ en poco tiempo comenzaron a verse experiencias similares en otros sitios del departamento, tal como ocurrió con las comunidades mestizas y campesinas de Bolívar e indígenas de Jambaló entre los años 2002 y 2003, hechos que lograron frenar por lo menos temporalmente las acciones armadas en estas regiones (Garcés, 2016).

Según Semelin (citado por Osorio, 2001), la resistencia civil tiene tres características: la primera, la afirmación de la identidad de los sujetos que resisten, que implica una toma de conciencia y afirmación de su propia dignidad, como vehículo para liberarse del miedo. Es así como la comunidad de Caldono recuperó su dignidad y afianzó en su autonomía al superar el miedo que producía la presencia de actores armados en su territorio al enfrentarlos con acciones firmes, pero no violentas. La segunda característica, la no cooperación colectiva, en términos de desobediencia y no colaboración con quien ejerce la dominación o el poder, en este caso por la vía armada, manifestada por los caldoneños al hacer explicita su posición de neutralidad como población civil frente a los actores armados estales y no estales, y la tercera, la obtención del respaldo de terceras fuerzas que apoyen su causa, lo cual implica buscar otros interlocutores externos y en la opinión pública un "contrapoder", para el caso de Caldono estos actores estuvieron representados por la iglesia católica y la Defensoría del Pueblo y, posteriormente, por otras organizaciones que apoyaron sus procesos de resistencia.

De esta manera los actos de resistencia se constituyeron en mecanismos que contribuyeron a dignificar a esta comunidad, a ejercer un rol activo en la búsqueda de la paz y la convivencia y con ello a recuperar su territorio. Arias (citando a Foucault, 1999) considera que la resistencia es portadora de una condición afirmativa más que defensiva, pues constituye nuevas maneras de vivir y relacionarse con sí mismos y con otros, en el marco de unas relaciones asimétricas de poder que resultan alteradas y transformadas. De allí su impacto directo en la salud mental colectiva, pues, se transforma el miedo, la rabia, la impotencia, la sumisión frente a la fuerza y el poder de las armas en acciones que contribuyen al empoderamiento comunitario, al 
fortalecimiento de los procesos organizativos interétnicos, a la recuperación de la autonomía sobre el territorio como espacio vital y con ello a tramitar los conflictos generados en la comunidad a partir del sufrimiento social generado por el conflicto armado, convirtiéndose entonces en un mecanismo de autoreparación de los daños causados.

\section{Conclusiones y Recomendaciones}

Esta experiencia investigativa se convirtió en todo un desafío emocional para los investigadores pues, la crueldad de los relatos y ser contados con tantos detalles, permitió avizorar lo que pudieron vivir estas comunidades, evidenciar que las inequidades sociales se acentúan en situaciones de conflicto armado y que la carencia de oportunidades para los jóvenes rurales favorecen su vinculación a los grupos armados legales o ilegales, tomarle el pulso a la salud mental de un pueblo en donde cada esquina guarda las memorias de hechos dolorosos, son realidades que solo pueden evidenciarse a través de estos procesos, pues los medios de comunicación, a través de los cuales ha llegado este tipo de información, o son manipulados o se quedan cortos ante una tragedia tan abrumadora.

Fue también la oportunidad de evidenciar como los valores sociales de solidaridad, cooperación, dignidad, fraternidad y capacidad organizativa posibilitaron afrontar eficazmente las situaciones más difíciles y lograr el empoderamiento que posibilitó los procesos de resistencia.

La comunidad del Municipio de Caldono ha visto comprometida su salud mental colectiva por un conflicto armado que tuvo como escenario su territorio, comprometiendo sus formas de vida familiar y comunitaria, la económica, las dinámicas del sector educativo, entre otras, dejando huellas imborrables en las historias familiares y comunitarias que aún hoy están visibles y que requieren de procesos reparadores que deben partir del reconocimiento de las capacidades, valores y potencialidades que tienen y que han desarrollado y fortalecido como mecanismo de supervivencia y de defensa de su territorio.

Al identificar los impactos de la violencia en la salud mental colectiva de esta comunidad, se evidencia la necesidad de que los profesionales de enfermería y de las ciencias sociales se apropien del concepto de geografía del cuidado como una herramienta para comprender e intervenir problemáticas que comprometen la salud mental colectiva, de tal manera, que sus acciones conlleven a reconocerla como una relación armónica de la triada familiacomunidad-territorio. Para que desde allí, se generen propuestas concertadas que reconozcan los valores y potencialidades comunitarias, sus procesos organizativos, sus estrategias para afrontar las dificultades, las dinámicas familiares y comunitarias en relación con el territorio, el reconocimiento de la diversidad étnica como una potencialidad y de los lugares, espacios y territorios como categorías de análisis determinantes en la salud mental colectiva que trascienden las delimitaciones políticas o sus características geográficas.

El conflicto armado logra afectar significativamente y en el largo plazo la salud mental colectiva, mediante la generación de una percepción general de miedo, dolor, impotencia, desarraigo, desesperanza, discriminación social y abandono estatal. Sin embargo, esta comunidad, ante la permanencia en el tiempo de un conflicto cada vez más agudo, logró desarrollar mecanismos para la defensa de su territorio como espacio vital, encontrando en la resistencia comunitaria la única posibilidad de recuperar la autonomía, la dignidad y el derecho a vivir en paz.

Frente a un escenario de "post acuerdo" y conociendo las limitaciones de talento humano en salud, se requiere fortalecer las competencias de los profesionales de enfermería principalmente para el desarrollo de intervenciones con enfoque psicosocial, la 
habilidad de proponer intervenciones para la promoción en salud mental, el trabajo interdisciplinario e interinstitucional y el reconocimiento de los procesos de abordaje de la salud mental desde los saberes ancestrales, entre otros, con el fin desarrollar procesos de cuidado que contribuyan a transitar hacia un escenario de convivencia y reconciliación.

Finalmente, se hace necesario incentivar el desarrollo de proyectos investigativos que contribuyan a comprender la complejidad de las afectaciones que, sobre la salud mental colectiva, ha dejado el conflicto armado y a reconocer el rol que los actores comunitarios han tenido en la construcción de la paz, la convivencia, el perdón y la reconciliación.

\section{Agradecimientos}

Los investigadores manifiestan sus agradecimientos a los hombres y mujeres participantes de esta investigación que desde el compartir generoso de sus historias, vivencias y acciones han contribuido a acariciar la posibilidad de vivir en un país en paz, en donde las heridas dejadas por la guerra en la salud mental colectiva son sanadas desde la solidaridad, la reconciliación y el empoderamiento comunitario. Este trabajo fue financiado con recursos propios del equipo investigador.

\section{Referencias}

Alcaldía Municipal de Caldono. (2017). Consolidado de Víctimas Conflicto Armado.

Arias-López, B.E. (2014). La potencia de la noción de resistencia para el campo de la salud mental: Un estudio de caso sobre la vida campesina en el conflicto armado colombiano. Salud Colectiva, 10 (2), 201211. Recuperado de: http://www.scielo.org.ar/scielo.php?script $=$ sci_arttext $\&$ pid $=$ S 1851 82652014000200005
Bang, C. (2014). Estrategias comunitarias en promoción de salud mental: Construyendo una trama conceptual para el abordaje de problemáticas psicosociales complejas Psicoperspectivas, 13 (2), 109-120. Recuperado de: http://www.redalyc.org/pdf/1710/171031 011011.pdf

Foucault, M. (1999). Estética, ética y hermenéutica: Obras esenciales. Volumen III. Barcelona: Paidós.

Garcés, A.R. (2016). Identidades, territorios y conflictos: Hacia una antropología contextual e histórica en el Cauca, sur de Colombia. Jangwa Pana, 15 (2), 223 - 239.

Gómez, C; Tamayo, N; Buitrago, G; Guarnizo, C; Garzón, N; Eslava, J; de Vries, E; Rengifo, H; Rodríguez, A. \& Rincón, C. (2016). Violencia por conflicto armado y prevalencias de trastornos del afecto, ansiedad y problemas mentales en la población adulta colombiana. Revista Colombiana de Psiquiatría, 45 (1), 147$153 . \quad$ Recuperado de: http://www.scielo.org.co/pdf/rcp/v45s 1/v 45s 1a20.pdf

Ministerio de Salud y Protección Social (2013). Plan Decenal de Salud Pública 2012 2021. Bogotá.

Osorio, F. (2001). Entre la supervivencia y la resistencia. Acciones colectivas de población rural en medio del conflicto armado colombiano. Cuadernos de Desarrollo Rural. Revista Javeriana, 47, 55 - 80. Recuperado de:

http://revistas.javeriana.edu.co/index.php/ desarrolloRural/article/viewFile/2065/130 9

Pardo, Y. \& González, M. (2007). Espacio y territorio en la práctica de enfermería 
comunitaria. Revista Aquichan, 7 (2), 189

- 198. Recuperado de:

http://aquichan.unisabana.edu.co/index.ph p/aquichan/article/view/112/225

Pozzi, D. \& Tansini, M. (2013). Documental Resistencia Comunitaria [Archivo de Video]. Recuperado de: https://www.youtube.com/watch?v=ko55 oJtJNfY

Hewitt, N., Juárez, F., Parada, A. J., Guerrero, J., Romero, Y. M., Salgado, A. M., \& Vargas, M. V. (2016). Afectaciones psicológicas, estrategias de afrontamiento y niveles de resiliencia de adultos expuestos al conflicto armado en Colombia. Revista Colombiana de Psicología, 25 (1), 125 140. DOI: $10.15446 /$ rcp.v25n1.49966

Rodríguez, J; De La Torre, A. \& Miranda, C. (2002). La salud mental en situaciones de conflicto armado. Revista Biomédica, 22, 337 - 346. Recuperado de: https://www.revistabiomedica.org/index.p hp/biomedica/article/viewFile/1183/1298

Tobón, F.A. (2005). La salud mental: una visión acerca de su atención integral. Revista Facultad Nacional de Salud Pública, 23 (1). Recuperado de: http://www.redalyc.org/pdf/120/1202311 3.pdf

Torres, F. (2017) Perspectivas para la intervención en lo social desde los retos del proceso de paz colombiano. Jangwa Pana, 16 (1), 112 - 121 pp. DOI: 10.21676/16574923.1961

Zurro, A.M. \& Solà, G.J. (2011). Atención familiar y salud comunitaria. España: Elsevier. Recuperado de: http://paginas.facmed.unam.mx/deptos/sp /wp-content/uploads/2013/12/anexo-133APS_Martin-Zurro-y-Jodar.pdf 